Article

\title{
Interpreting Circularity. Circular City Representations Concealing Transition Drivers
}

\author{
Julie Marin * (D) and Bruno De Meulder \\ Department of Architecture, University of Leuven, 3000 Leuven, Belgium; bruno.demeulder@kuleuven.be \\ * Correspondence: julie.marin@kuleuven.be; Tel.: +32-16-37-43-80
}

Received: 30 January 2018; Accepted: 17 April 2018; Published: 24 April 2018

check for updates

\begin{abstract}
Embodying circular economy transition as a sustainable city concept, circularity in cities is increasingly the subject of policy innovations, urban strategies, and research \& development agendas. It seems evident that a circular city should include more than the sum or multiplication of urban circular economies. Nevertheless, prevailing discourses remain till today business focused, and how circular economy creates economic, social, and environmental resilience in cities has yet to be explored. This paper conceptualizes the notion of urban circularity. It introduces an analytical framework sorting existing circularity concepts that are based on design and planning characteristics. Adopting comparative case study research on four contemporary forward-looking spatial representations of 'circular' places, this paper articulates their circularity interpretation. Demonstrating how diverging sustainability framings and political positions are embedded within the studied spatial representations, this paper aims to bring clarity in contemporary circular city approaches for policymakers as well as for spatial practitioners. The paper concludes with an agenda for multi-perspective and multi-dimensional circular city design, which is anchored in place specific and multi-scalar transition relations. It suggests urban landscape design as a disciplinary field to act as a pivot in transdisciplinary circularity design and research.
\end{abstract}

Keywords: circular economy; circular city; transition; urban landscape design; comparative case study research; future imaginaries

\section{Introduction}

\subsection{Circular Economy in Theory and Practice}

The circular economy concept originates in ecological and environmental economics and industrial ecology [1,2]. It can be brought back to Kenneth Boulding's work pointing out the limited natural resources that are available for human activities [3], Georgescu-Roegen's work on thermodynamics in economic systems dictating matter and energy degradation from 1971 [2] and Frosch and Gallopoulos' 1989 Strategies for Manufacturing article [4]. Circular economy is an evolving 'umbrella' concept embodying internal complexities and multiple definitions. Only recently the scientific community initiated conceptual discussions about circular economy definitions [2,3,5-7]. Additionally, the first scientific research frameworks for circular economy start to be developed $[1,8]$. In their consensus definition, Pietro-Sandoval et al. propose a basic notion of circular economy as "an economic system that represents a change of paradigm in the way that human society is interrelated with nature and aims to prevent the depletion of resources, close energy and materials loops, and facilitate sustainable development through its implementation at the micro (enterprises and consumers), meso (economic agents integrated in symbiosis) and macro (city, regions and governments) levels. Attaining this circular model requires cyclical and regenerative environmental innovations in the way society legislates, produces and consumes" [7] (p. 613). 
Nevertheless, even though scientific circular economy theory is in its early development, policy and practice are moving forward with it [1]. They primarily adopt and implement the circular economy to decouple economic growth from primary resource extraction through reuse, repair, and recycling [9]. Early 20th century industrials, such as Henry Ford, already maximally reused waste products with the objective to optimize human labor and expenses and to save capital (rather than resources) [10]. From the 1970s onwards, resource conscious economic models were mainly driven by attention for the planet's limited resources, as raised by The Club of Rome [11]. Today, the United Kingdom-based Ellen MacArthur Foundation (EMF) aims to accelerate circular economy transition, combining elements from ecology, systems thinking, and environmental economics [12] (p. 3). The EMF promotes circular material flows and the separation of biological from technological materials drawing from environmental engineering's Cradle-to-Cradle concept. Additionally, the EMF's circular economy refers to Stahel's 'closed loop' Performance Economy, Benyus' nature-inspired innovation or Biomimicry, Industrial Ecology, Natural Capitalism viewing economy as dependent on the global environment, Pauli's Blue Economy, and Tillman Lyle's Regenerative Design [13]. Another key principle in the EMF circular economy frameworks is smart city technology, enabling efficient monitoring of resource flows [14].

However, a substantial amount of circular economy theory and practice tends to forget about social equity and 'reducing' materials use [5], prioritizing recycling in growth-oriented economic systems [2]. Indeed, economist Arnsperger and philosopher Bourg state that circular economy as advocated by frameworks, such as Cradle-to-cradle or the EMF circularity framework, is not 'authentic' since these frameworks only take into account the resource flows entering production systems at the micro enterprises or sectors level. Supporting fundamentally extractive capitalist logics, these circular economy forms do not reduce net resource consumption implying cutting down consumption and economic growth. Arnsperger and Bourg state that an authentic circular economy should leave behind the economic growth paradigm and focus on reducing resource usage on a systemic level [15].

Scientific circular economy research mainly takes place in China and Europe since the beginning of the millennium, as a result of public policies in these geographical areas [3]. China adopted circular economy to deal with pollution issues that were related to China's rapid growth, while Europe focuses more on business opportunities and resource efficiency [16]. According to Korhonen et al. the research majority focuses on applied circular economy, emphasizing tools, metrics, and measures within the engineering and natural sciences fields, while research on circular economy as a paradigm, its norms, values, underlying worldviews, visions, and concepts, remain largely unexplored [1]. In order to achieve circular economy as a paradigm shift, they argue that a shift is required in "the basic philosophy of culture and societal development in the global society" supported by qualitative social sciences research [1] (p. 550).

\subsection{Circularity and its Spatial Articulation Remain Confusing}

Embodying circular economy transition as a sustainable city concept, circularity is increasingly the subject of policy innovations, urban and regional strategies, research, and sustainability visions. The European Union's 2015 Circular Economy Package proposes a legislative frame stimulating competitive and sustainable circular economy [17]. The Ellen MacArthur Foundation, who primarily supports business-driven circular economy, launched a global Circular Cities network in 2016 [18]. Furthermore, cities taking circular economy initiatives emphasize different aspects. In Amsterdam, 'the circular city' is one of the themes covered by the 'smart city' [12] (p. 14) [19,20], Glasgow connects and supports companies to develop circular economy [12] (p. 12) [21], and Paris counts households amongst primary actors in circularity transition [22]. However, when it comes to defining circularity in cities, in this text referred to as 'circular cities', substantial confusion arises. For example, Prendeville et al. who studied six cities in circular economy transition through stakeholder interviews and policy documents, conclude that circularity is often conflated with sustainability, and is connected to different ambitions and definitions, while policymakers lack direction on how to realize circular cities. [12] 
(p. 18). In order to create clarity in what circular cities entail, explorations of the 'circular city' as a socially, environmentally, and economically resilient city supported by circular economies are urgent but have only just begun [23].

If circular economy is generally nowadays a 'guiding' image for circularity in cities, the future 'circular city' remains a rather blurred image. Even though circular economy research frameworks are still under development (see Section 1.1), circular city projects and imaginaries do exist and spatially articulate circularity. These circular city representations emphasize varying circularity drivers, ranging from technology-driven resource efficiency (see Section 3.1.2) to activism-induced resource equity (see Section 3.1.3). In short, they conceal transition drivers leading to varying circularity interpretations. However, even though circular city representations spatialize specific sustainability framings and the associated ideological positions, these framings generally remain unarticulated, creating confusion about the imaginaries' statuses. Therefore, this research addresses the question of how to define circularity in cities by comparing and dissecting four 'circular city' imaginaries representing diverging sustainability framings. On one hand, certain images appear to be mere celebrations of technological progress, proposing generic solutions, such as green roofs and facades (see Section 3.1.1). On the other end of the spectrum, images not necessarily claiming to articulate circularity, integrate nature, culture, and society in place-specific circular configurations (see Section 3.1.4). The study goal is to clarify different sustainability framings for 'circular cities' as well as potential drivers defining circularity.

\subsection{Circularity Is Multi-Scalar,-Dimensional and Place-Specific}

Transition from linear to circular economy is one of many ongoing sustainability transitions to reach more environmentally sustainable development. It is a complex multi-actor, multi-level, multi-phase, and multi-pattern process [24,25]. Recognizing that transition takes place in particular places in the physical world, the Geography of Sustainability Transitions field calls for understanding sustainability transitions' "place-based and multi-scalar characteristics conditioning the required systemic changes" [26]. Nevertheless, Coenen et al. draw attention to the fact that transition's spatial dimensions remain largely unexplored in transition literature [27]. Even though consensus exists that place-specificity matters, insights on how place-specificity matters for transition concretely is lacking [27] (p. 21).

Research on circular economy implementation in a European context as well as empirical knowledge on circular economy spatial practice is rare [12] (p. 3). Furthermore, existing circular economy frameworks, such as the EMF's model of circular bio cycles and techno cycles, represent product and material flows in a conceptual and simplistic way and do not sufficiently integrate social factors [12] (p. 3). According to Pomponi and Moncaster [8], current circular economy research in the built environment seems characterized by partial approaches, not truly accounting for the complexity of all the dimensions involved. Therefore, they advocate for interdisciplinary research weaving together technical focuses and wider social, economic, and environmental perspectives that are essential to promote and implement multi-dimensional circularity. Nevertheless, based on a literature review on the available framings of circular economy research, they defined six fundamental dimensions for circular economy research in the built environment: environmental, technological, economic, societal, governmental, and behavioral [8]. In conclusion, most circular economy approaches present policy or business frameworks and to date frameworks for designing multi-dimensional circular cities are missing.

\subsection{Towards a Circularity Drivers Framework for Spatial Practice}

Ultimately circular economy and circularity take place in space. Therefore, this paper proposes a spatial reflection on circularity, which is aiming to construct knowledge on future circular cities' potential development drivers. This paper compares four contemporary circularity spatial representations to build up a spectrum of circular city design drivers. Briefly discussing the cases' context and content, the paper analyses the particular settings of the imagined circularity transitions. 
Revealing very distinct circular futures approaches in the four studied cases, this paper firstly aims to bring clarity for policymakers and spatial practitioners in currently confusing 'circular city' approaches. The comparative research demonstrates that the addressed drivers behind circularity imaginaries highly depend on the commissioner and disciplinary field realizing the future imaginary. Some imaginaries are very straightforward but they exclude certain drivers, while others are more nuanced and have the capacity to gradually add circularity drivers. Secondly, the paper builds up a conceptual circularity design framework for multi-perspective and multi-dimensional circular city design, addressing place specificity and multi-scalar transition relations. It suggests that the urban landscape design discipline has the capacity to address multi-scalarity and place-specificity in circular city transition, reflecting a constructivist and holistic sustainability framing.

\section{Materials and Methods}

\subsection{Comparative Case Study Research}

Case study research is a common method in architectural research [28] and the social sciences. It is adopted to study particular situations in depth and to narrow down broad research topics. Rather than aiming for right or wrong answers, case studies support reasoned debate based on interpretation [29].

"A case study is an empirical enquiry that investigates a contemporary phenomenon within its real-life context, especially when the boundaries between phenomenon and context are not clearly evident" [30] (p. 13).

According to Yin's definition, case study research seems appropriate to start exploring and understanding the topic of circular cities. Indeed, circular cities exploration is in its initial phase [12,23] and is rather complex. In fact, as with any sustainability transition, circular city transition poses a structurally complex wicked problem for which no definitive answer might exist. Wicked problems [31] have no clear solutions or goals to reach up until the moment they are achieved. It's unclear where they begin or stop and they might have multiple solutions or remain unresolved [32,33]. With fewer established rules and procedures than other research designs, the case study method focuses on the embeddedness of cases in their context, the richness of multiple data sources, as well as their ability to generalize to theory [28].

This article adopts case study research to start exploring, describing, and explaining [30] complexity and multiple facets of the selected cases in depth [28]. The case study research design is guided by theory development on circularity interpretations. Given this task's complexity, it should be considered as an empirical introduction to the subject.

The research compares four different circular city imaginaries' contexts and spatial outcomes, selected as follows:

- Content: The object of study is a realized or unrealized spatial circularity representation.

- Scale: Referring to Sandoval et al.'s definition (see Section 1.1), the object of study is a macro scale project (a site in relation to its larger context, a neighborhood, a city or a region).

- Circularity: The project either literally states circularity or implicitly alludes to circularity through graphical closed resource loops representations.

- The project was initiated in the last ten years.

Finally, four cases were selected from a longlist, with the objective to represent maximally diverging sustainability framings for circularity according to Philippe Vandenbroeck's framework for urban metabolism spatial practices (see Section 2.2).

The cases are Reburg (Flanders, Belgium), r-Urban (Colombes, Paris, France), Masdar City (Abu Dhabi, United Arab Emirates) and Living Breakwaters (Staten Island, New York, NY, USA).

The comparative study draws from multiple sources. Besides desktop research, the selected cases were physically or virtually visited. Semi-structured stakeholder interviews were performed during the site visits (see Table 1). 


\subsection{Analytical Framework for Urban Metabolism Spatial Practices by Philippe Vandenbroeck}

The case study analysis builds onto Philippe Vandenbroeck's framework for urban metabolism spatial practices $[33,34]$. Vandenbroeck, bio-engineer, philosopher, and planner, developed this framework as a reflection on a masterclass series entitled Designing with flows. Towards an Urban-Metabolic agenda for a Circular Future, which was organized by the Flemish Waste Association (OVAM), Architecture Workroom Brussels, and the Flemish Chief Architect in 2016 and 2017. The masterclasses aimed to "stimulate the development of an urban-metabolic agenda and to initiate participation and co-operation at the various spatial and inter-governmental levels" [35]. In three sessions policymakers, engineers, architects, and urban landscape designers, debated on urban metabolism, what change is required and where to start implementing the change [36]. The Designing with flows masterclasses were mainly steered by OVAM's circular economy transition program. As a European forerunner in recycling and sustainable resource management programs [37], the OVAM recognizes the potentially broad interdependency between circular economy transition and spatial development. Therefore, its interest in urban metabolism spatial practice. However, in the masterclasses, 'urban metabolism' did not refer strictly to industrial ecology's quantitative material flow analysis approaches [38]. Here 'urban metabolism' was rather adopted as an umbrella for diverging circularity approaches within spatial practice. This interpretation resonates with Castan Broto et al.'s conclusion that the urban metabolism concept travels across disciplines and it is most often applied to push the boundaries of their own field towards multidisciplinary approaches and dialogues [39] (p. 851).

Vandenbroeck's framework organizes urban metabolism spatial practices according to their dominant sustainability framings, bringing clarity in how different disciplines have diverging approaches to urban metabolism questions. The framework articulates that a metabolism driven governance and design practice can result in very different futures, depending on this practice's conception of space [34].

According to Vandenbroeck, a fundamental difference in urban metabolism spatial practices lies in an objectivist versus a constructivist worldview (Figure 1a). A worldview is "a set of beliefs, symbols, values, and segments of objective knowledge that are widely shared in a given society over a considerable period of time" [40]. For Vandenbroeck, the objectivist worldview focuses on performance and efficiency, and it intervenes in space 'from the outside', considering people as objects of control, human resources, or rational utility maximizers. Contrarily, the constructivist worldview focuses on potential, acting from within the intervention space with situational materials and resources, such as people [34]. A parallel can be drawn with science philosophy, as described by Beinfield and Cornold [41]. The objectivist worldview resonates with western science philosophy based on the premise that humans are independent from nature, and that the world, like a machine, can be dismantled and brought back to its constituent parts. Reality can be measured, quantified, and analyzed. In line with 17th century French mathematician Descartes, imagining the world as a machine, exact sciences were conceived to dominate and rule nature [41]. On the other hand, the constructivist worldview resonates with ancient philosophy. The center of most ancient societies, from European pre-medieval cultures [40] to China in the second century before Christ or indigenous America in the twentieth century, was the earth. Most ancient societies drew their power from nature and strived for harmony with the seasons, the rhythms and patterns that connect things to each other [41]. In a metaphorical nutshell, the objectivist spatial practitioner could be considered like a technician, mechanically intervening in urban resource flows to make the metabolism work. On the other hand, the constructivist spatial practitioner could be considered like a gardener, skillfully guiding resource flows with flexibility and openness.

Another dichotomy that Vandenbroeck reveals in urban metabolism spatial practice is spatial structures that are based on relationships of proximity versus spatial structures that are based on relationships of connectivity (Figure 1b). The two above conceptualizations Vandenbroeck combines in four typologies of metabolism approaches, crossing the two conceptual dimensions: pool table, web, mosaic, and narrative metabolisms (Figure 1c). 


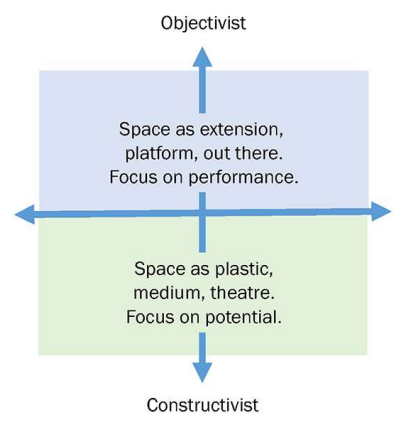

(a)

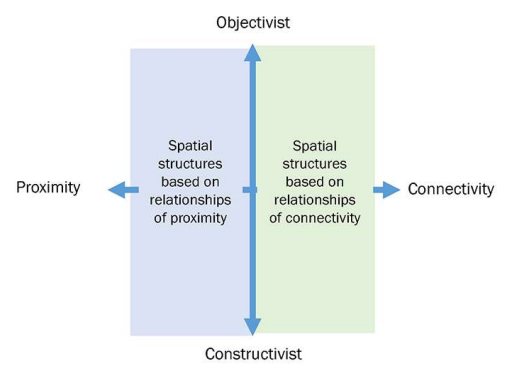

(b)

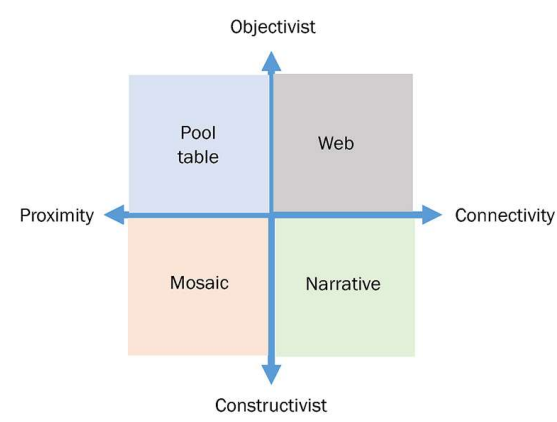

(c)

Figure 1. Vandenbroeck's framework for urban metabolism spatial practices (2017). (a) objectivist versus constructivist spatial conceptualization, (b) proximity versus connectivity (c) four metabolic ways of looking at the world.

In a draft paper entitled A metabolic way of looking at the world [34], Vandenbroeck expands on the four typologies that are derived from the combinations of different ways of looking at the world. In other words, on the different sustainability framings. The four typologies are based on the assumption that the concept of space was thoroughly rethought throughout the twentieth century. Conceptually, this led from an objectifying perspective to an internal perspective and from a structure in terms of physical proximity to a structure in terms of connective networks. These two movements can be placed onto each other orthogonally resulting in four types of spatial conceptions [33,34]. Pool table metabolisms consider space as a carrier of metabolic flows, which is mastered from the top down as an efficient machine. The pool table approach focuses on efficient resource flows evoking environmental and economic gains through engineering and management. Secondly, web metabolisms materialize in the smart city concept, focusing on the optimal use of urban assets aiming for environmental and economic advantages and an increased 'convenience' and safety. Contrarily to pool table and web metabolisms, mosaic metabolisms are embedded in a development model specific to a biological, cultural, topographical, and infrastructural territory. They are essentially emancipatory, aiming to develop a relationship between humans and space. As such, mosaic metabolisms aim to restore ecological balances and to reinforce cultural identity by rearticulating the historical link between city and hinterland. Finally, narrative metabolism is the most complex typology to grasp. Narrative metabolisms are not coherent and unstable; they are the result of a-synchronic and a-symmetrical overlapping and overcrossing networks and 'idiorhythmic' settings. They focus on the creation of conditions for an always precarious way of living together [34]. Vandenbroeck's four typologies reflecting 'different metabolic ways to look at the world' serve as a basis to start interpreting four case studies' ideologically different sustainability framings. Firstly, Section 3 briefly describes the four selected spatial circularity representations. Secondly, Section 4 interprets Vandenbroeck's framework to compare the four cases, while starting to expand the framework with a spectrum of circularity drivers.

\section{Results}

\subsection{Four Circular City Representations}

\subsubsection{Reburg}

Reburg is a future projection of "the world's most circular city", which was produced by foresight and design studio Pantopicon in 2015 (Figure 2a). Reburg's commissioner is Circular Flanders (Vlaanderen Circulair, previously Plan-C), a partnership between governments, companies, civil society, and knowledge centers taking action to achieve circular economy in Flanders [42]. Reburg visualizes how life would look in a circular city, what type of companies would thrive there and how the circular city would materialize. On Reburg's website, Reburg citizens, such as Zoë the 
Urbaculturalist, take visitors on a tour of circular manufacturing, consumption and end-of-life facilities, such as a fabcenter, where young innovators engage in local manufacturing, a revive lane where machines are refurbished into new applications, optimized loops and circular coffee shops. Innovation and circular economy business opportunities are at Reburg's core. Reburg's resulting image is an imaginary city collage of state-of-the-art technology such as green roofs and drone transportation and circular economy business models, such as short circuit production using waste as a resource. Conceived by scenario planners, Reburg spatializes a potential development direction for circular economy, as supported by Circular Flanders. It provides a framework for innovators and society, "to provoke their thinking on the circular economy and engaging the audience in follow-up episodes of circular futures" [43]. Figure 2b conceptualizes Reburg's urban scheme: focus is on closing material flows through urban economies in an imaginary city. Ports, stations, and hubs play a pivotal role as connecting points for multi-scalar resource cooperation, managing material flows at the most immediate or local level where they can effectively be reused.

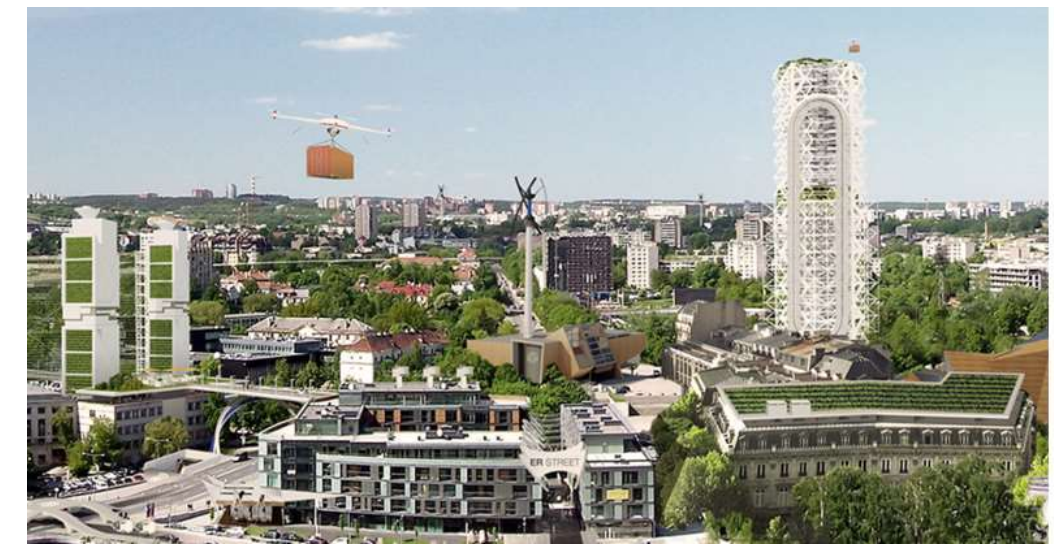

(a)

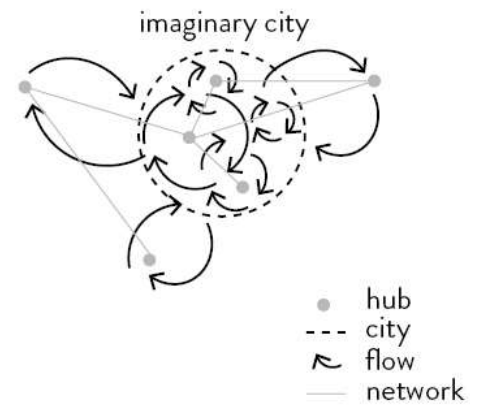

(b)

Figure 2. (a) Reburg imaginary by Circular Flanders \& Pantopicon (2015), based on original photograph by Jan Mehlich [44]; and, (b) Simplified urban diagram by authors.

\subsubsection{R-Urban}

R-urban by the Parisian Atelier d'Architecture Autogérée (AAA) is a generic bottom-up urban resilience strategy in European cities, creating "a network of locally closed ecological cycles linking economy, habitat, mobility, urban agriculture and culture and using land reversibly" [45]. Similar to the Transition Towns Movement [46], R-urban adopts a political ecology approach: it is a political critique of dominant capitalist sociotechnical regimes. Through pilot projects and collective facilities, R-urban tries to "reveal the solidarity networks and ecological cycles that it creates" [47]. R-urban essentially consists of a charter on how communities and individuals can act against global climate change and resource scarcity crises. Adherence to the R-urban network, existing since 2008, means the engagement of a community to initiate local circular initiatives, such as community gardens, composting, rainwater harvesting, and materials recycling. AAA initiated a pilot project in close collaboration with the community in Colombes near Paris in 2012, with a Recyclab, a community run recycling lab, and Agrocité, an agricultural and cultural community center. After the launch and a few years of collaboration, AAA left Agrocité in the hands of the community who took full ownership of the project. It understands circularity as production of commons: a civic and ecological economy, developing from the bottom-up. R-urban essentially deals with existing urban fabrics and sociopolitical contexts that are aiming "to achieve environmental sustainability, societal change and reinvention" [47] (p. 65). R-urban's core image shows a network of community spaces, such as housing blocks and community gardens, connected through locally closed ecological cycles (Figure 3). The strategy is applicable in any community who wants to contribute to shaping a resilient future. 
Figure 3b shows R-urban's urban scheme: focus is on locally closing resource loops working with a specific community's available assets and resources.

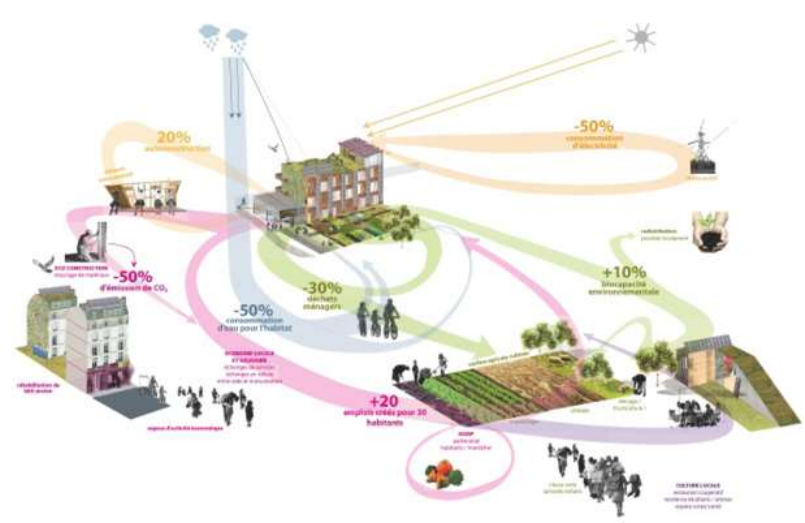

(a)

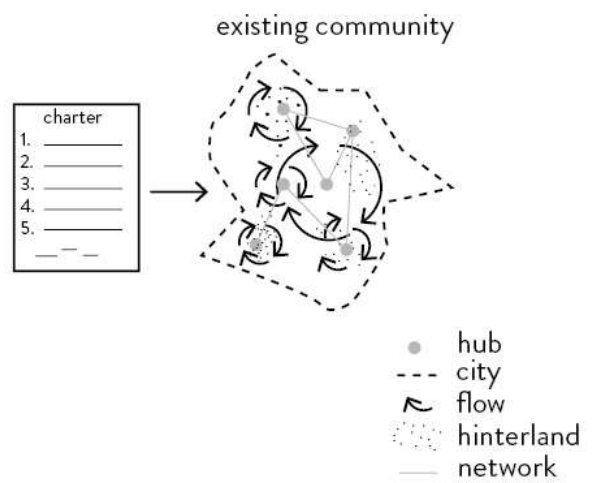

(b)

Figure 3. (a) R-urban strategy principles by Atelier d'Architecture Autogérée (AAA) [48]; and, (b) Simplified scheme of resource flows by authors.

In February 2017, AAA's Agrocité was forcefully removed from Colombes by the mayor, to be replaced by a parking lot for 182 vehicles. Another nearby municipality, Gennevilliers near Paris, volunteered to recover the pilot project buildings and structures $[49,50]$.

\subsubsection{Masdar City}

The United Arab Emirates Masdar City construction, which was the world's first "zero waste, zero carbon and fossil fuel free" city, started in 2008. Images of Masdar City show the new city as a lush new town surrounded by the desert transformed into productive solar panel fields (Figure 4a). Abu Dhabi's renewable energy company developed Masdar City aiming to diversify its economy beyond oil [51]. Masdar, meaning 'resource' in Arab, is located in the desert at about $17 \mathrm{~km}$ from Abu Dhabi. "The city design reflects the precepts of the circular economy, in which industrial networks are designed to mimic the cyclical behavior of natural ecosystems" [52]. Masdar City strives for the highest quality of life with the lowest environmental impact. The city itself is designed for pedestrians and is connected to Abu Dhabi through a personal rapid transit driverless electric vehicle system for people and freight. Energy efficiency is obtained through a combination of high-end technology and vernacular building methods. The architects' team, led by Norman Foster, drew inspiration from traditional settlement typologies, such as low-rise and compact Arabian cities' narrow street layouts and building orientations, working with natural ventilation towers, shade, water features, and green spaces for cooling. Masdar desalinates sea water and reuses waste materials and resources maximally, such as wastewater for the landscape maintenance. At Masdar City's core lies a knowledge institute for sustainability, with a special economic zone to attract green companies and clean tech businesses. As Figure $4 \mathrm{~b}$ schematically shows, resource flows are closed within Masdar City's boundaries, importing new materials and resources to construct Masdar City from scratch in the desert. 


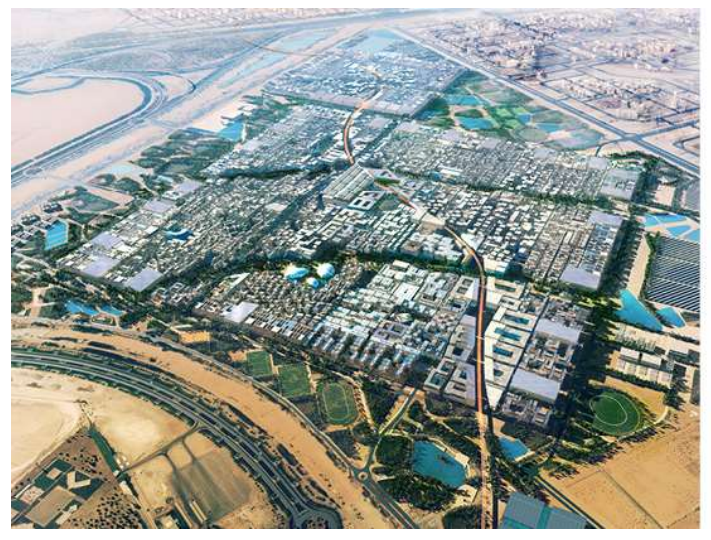

(a)

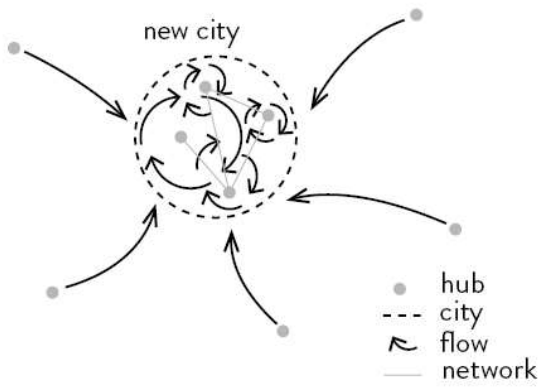

(b)

Figure 4. (a) Masdar City imaginary by Foster and Partners [53]; and, (b) Simplified urban scheme by authors.

Today, the aims of Masdar City as a model of sustainable living have been partially abandoned. Only 300 people effectively live in the city that has only been completed for $5 \%$ of the original plan. The autonomous vehicle system was abandoned after two of the planned hundred stops were built because new automotive technologies made it obsolete. Bike sharing systems were put in place, but are underused because of the absence of bicycle paths between Masdar City and Abu Dhabi. According to the design manager "The original aim was to be net zero, yes, but that was when we were looking at the city in isolation" [54].

\subsubsection{Living Breakwaters}

Staten Island's Living Breakwaters project combines "coastal resiliency infrastructure with habitat enhancement techniques and environmental stewardship models, linking in-water protective interventions to on-shore resiliency and community engagement" [55]. The project is part of the federally funded New York Rebuild by Design Competition after Hurricane Sandy in 2012. Rebuild by Design adopts "collaborative, design-driven problem-solving to help communities and cities build resilience" [56]. It commissioned urban and landscape design firms to co-design strategic visions to rebuild New York's affected shores. The Staten Island zone was commissioned to New York City's urban landscape design firm Scapestudio, in collaboration with many technical and local experts, such as ocean, coastal, and ecological marine consultants and the New York Harbor School. Starting with thorough multi-scalar spatial site analysis, from regional flood risk to small-scale reef habitats, and interviews with local actors, Living Breakwaters integrates risk reduction, culture, and ecology in an urban landscape strategy. This circularity interpretation is articulated in the top left image corner (Figure 5a). Referring to the area's historical storm water protection by a series of oyster reefs, Living Breakwaters proposes a series of offshore constructed reefs that are gradually building up a coastal protection system. Living Breakwaters' core image (Figure 5a) shows how the proposed structure works at multiple levels: firstly, the reefs attenuate storm waves and preserve or increase beach width. Secondly, the Living Breakwaters increase aquatic habitat diversity for oysters, fish, and shellfish. Thirdly, the project realization is fostered by a social resiliency strategy of community education programs and ecosystem stewardship, engaging citizens in the ecosystems that they inhabit. As such, people and material flows crossing Living Breakwaters' intervention site are interconnected with their bioregions exceeding the site's boundaries. (Figure $5 b$ ). 


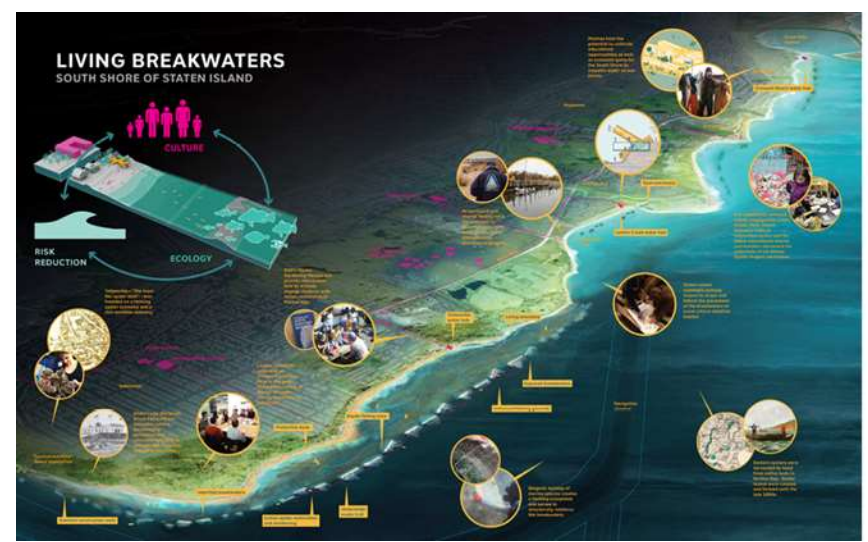

(a)

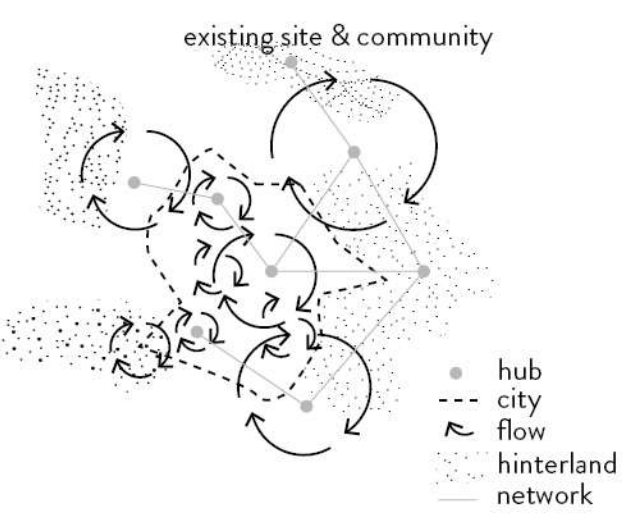

(b)

Figure 5. (a) Living Breakwaters by the SCAPE team [57] the Project aims to reduce risk and erosion, rebuild structural habitat for marine species, and foster social life on shore through NYC schools and the Billion Oyster project; and, (b) Simplified scheme of resource flows by authors.

The project realization simultaneously works at different levels: pilot projects are set up to test prototypes to construct the Living Breakwaters, while communities and harbor schools are involved in environmental protection programs. The government organizes educational programs, such as beach walks, to explain citizens the coastal processes at work. As such, throughout all of these initiatives and landscape (re)construction projects, the Living Breakwaters design functions as a guiding strategy for interweaving risk reduction, ecology, and culture, both within the community as well as within its larger bioregion [57].

Before comparing the cases in Section 4, Table 1 summarizes each case's main features.

Table 1. Summary table of the four case studies.

\begin{tabular}{|c|c|c|c|c|}
\hline & Reburg & R-Urban & Masdar City & Living Breakwaters \\
\hline Project question & $\begin{array}{l}\text { Imaginary of Circular } \\
\text { Flanders in } 2036\end{array}$ & $\begin{array}{l}\text { Bottom-up urban } \\
\text { resilience strategy }\end{array}$ & $\begin{array}{l}\text { First zero waste, zero } \\
\text { carbon, fossil fuel free } \\
\text { city }\end{array}$ & $\begin{array}{l}\text { Strategic spatial vision to } \\
\text { rebuild Staten Island shore }\end{array}$ \\
\hline Location & Somewhere in Flanders & $\begin{array}{l}\text { Anywhere, with pilot } \\
\text { project in Colombes, } \\
\text { Paris }\end{array}$ & $\begin{array}{l}\text { The desert } 17 \mathrm{~km} \\
\text { outside Abu Dhabi }\end{array}$ & $\begin{array}{l}\text { Staten Island shore, } \\
\text { New York City }\end{array}$ \\
\hline Scale & City & Neighborhood & City & Neigborhood-City-Region \\
\hline $\begin{array}{l}\text { Circularity } \\
\text { interpretation }\end{array}$ & $\begin{array}{l}\text { Urban solutions for circular } \\
\text { economies }\end{array}$ & Production of commons & $\begin{array}{l}\text { Net zero environmental } \\
\text { impact }\end{array}$ & $\begin{array}{l}\text { Integrating risk reduction, } \\
\text { ecology and culture }\end{array}$ \\
\hline Main agenda & Circular Economy & Political Change & Resource efficiency & $\begin{array}{l}\text { Site and context specific } \\
\text { resilience }\end{array}$ \\
\hline Goal & $\begin{array}{l}\text { Provoke out-of-the-box } \\
\text { thinking }\end{array}$ & $\begin{array}{l}\text { Inspire/Activate to } \\
\text { change the reigning } \\
\text { capitalist sociotechnical } \\
\text { regime }\end{array}$ & $\begin{array}{l}\text { Demonstrate a global } \\
\text { example of circular cities }\end{array}$ & $\begin{array}{l}\text { Guide the creation of resilient } \\
\text { shore communities and } \\
\text { landscapes }\end{array}$ \\
\hline Commissioner & Plan C & $\begin{array}{l}\text { Community-initiated } \\
\text { (by AAA in the case of } \\
\text { Colombes) }\end{array}$ & $\begin{array}{l}\text { Abu Dhabi Renewable } \\
\text { Energy Company } \\
\text { (Masdar) }\end{array}$ & $\begin{array}{l}\text { President Obama's Hurricane } \\
\text { Sandy Rebuilding Task Force }\end{array}$ \\
\hline Policy context & Circular Economy Transition & Activism & Sustainability transition & $\begin{array}{l}\text { Post-disaster recovery and } \\
\text { resilience }\end{array}$ \\
\hline Executer & Pantopicon 2015 & $\begin{array}{c}\text { Atelier d'Architecture } \\
\text { Autogérée (AAA) since } \\
2008\end{array}$ & $\begin{array}{l}\text { (phase one) Foster } \\
\text { +Partners et al. } \\
\text { 2007-2014 }\end{array}$ & Scapestudio et al. since 2013 \\
\hline $\begin{array}{l}\text { Main Disciplinary } \\
\text { field }\end{array}$ & Scenario planning & $\begin{array}{l}\text { Political Ecology and } \\
\text { Architecture }\end{array}$ & Industrial Ecology & Urban Landscape Design \\
\hline $\begin{array}{l}\text { Site-visits and } \\
\text { semi-structured } \\
\text { interviews }\end{array}$ & $\begin{array}{l}\text { Oct } 2016 \text { participant in } \\
\text { Reburg workshop } \\
\text { 'community meeting 2037' }\end{array}$ & $\begin{array}{c}\text { Feb 2015, site visits } \\
\text { Recyclab and Agrocité, } \\
\text { lecture by and } \\
\text { discussion with project } \\
\text { visionary and architect }\end{array}$ & $\begin{array}{l}\text { Oct } 2015 \text {, site visit and } \\
\text { guided tour as part of } \\
\text { Abu Dhabi Ecocity } \\
\text { World Summit } 2015\end{array}$ & $\begin{array}{l}\text { 2013, urban designer at } \\
\text { Scapestudio during the } \\
\text { project's design phase. } \\
\text { Not personally involved in } \\
\text { the project }\end{array}$ \\
\hline
\end{tabular}




\section{Discussion: Comparing Four Circularity Representations}

The four presented cases each interpret circularity fundamentally differently. Reburg proposes urban solutions achieving circular economy, r-urban proposes a civic and ecological bottom-up economy, Masdar City aims for net zero environmental impact, and Living Breakwaters for integrating culture, ecology, and risk reduction. The cases reflect transition's widely varying driving forces and divergent sustainability framings. The following section articulates these differences in interpreting Vandenbroeck's framework for urban metabolism approaches, which are outlined in the methods section [33,34]. Section 4.1 evaluates each case's spatial circularity interpretations as translations of different sustainability worldviews, associated disciplinary fields and commissioners. It also looks at the four case studies' policy and execution context, aiming to understand these differences. Secondly, Section 4.2 starts constructing a spectrum of circularity drivers for circular spatial practice.

\subsection{Interpreting Circularity from Different Sustainability Framings}

\subsubsection{Objectivist versus Constructivist}

Reburg and Masdar City clearly exemplify an objectivist worldview that is focusing on performance. Both of the projects start from a practically clean slate. Both of the cities are detached from any existing urban fabric, virtual in the case of Reburg, and physical in the case of Masdar City.

Reburg's goal is to accelerate circular economy through provocative scenarios for circular manufacturing and entrepreneurship. Within the boundaries of this question, Pantopicon's scenario planners envisioned urban technology and business solutions, inspired by global trends in circular economy innovations. This method to provoke out-of-the-box thinking could be effective when trying to spatially imagine circular economy from the agency perspective, addressing municipalities, businesses, and all sorts of organizations. However, Reburg's website seems to suggest that a circular city is simply the sum of circular economies in the city and appears as an attempt to build coherence into the 'Circularity Fair' of technological available and economical imaginable instruments. As a technocratic playing field for smart innovators and entrepreneurs, Reburg seemingly ignores any dimension outside professional urban life. This is surprising, since Reburg's commissioner Plan C represents multiple societal voices, such as transition network midfield, envisioning social equity, profound democracy, society-embedded economy, and ecological equilibrium between nature and humans [58]. These values hardly seem to be reflected in the Reburg imaginaries. Advancing Reburg images as the spatialization of a social and ecological 'circular Flanders' as in their Betergem 2038 [59] workshops therefore appears to be rather contradictory. This contradiction raises the question whether scenario planning's imaginaries, as adopted in this case, are rather literal guiding images giving a certain sense to individual operations it tries to simulate.

The third case study, Masdar City, embodies sustainability mostly from a techno-infrastructural perspective, using the opportunity of a new ecological district to experiment with the newest technologies supporting industrial symbiosis and circular economy. The team that was led by architect Norman Foster developed a qualitative spatial scheme combining traditional climatic urban design and building techniques with high-end technology. Focusing on resource efficiency and closing resource loops, this circular city approach essentially draws from industrial ecology; the disciplinary field optimizing resource flows between buildings in a given area. However, adopting industrial ecology in urban contexts has been critiqued for ignoring the interdependencies between resource flows and their hinterlands and for ignoring the relevant scales and actors that are related to these resource flows. [60], This critique indeed resonates with Masdar City's current withdrawal of its circularity goals when considering the city in isolation [54]. Even though the idea behind Masdar City as the world's first circular city can be considered to be revolutionary in Abu Dhabi's context of energy and materials engorging skyscrapers and developments, its conception in the middle of the desert and therefore the consumption of an entirely new piece of land at distance from existing amenities, can hardly be considered as 'circular'. Masdar City's high-end infrastructures and technologies might make its 
concept reproducible in any other country across the globe [61], yet recent evaluations indicate that it is lacking essential urban dimensions to become a successful urban realm [54]. Besides Masdar City's physical isolation, its conception of a city as a stable or fixed model, implementable ex novo, prevents Masdar City from gradually gaining a critical mass that allows integration and synergies as an ever evolving organism.

To summarize, Masdar City and Reburg embody objectivist sustainability framings:

- Adopting techno-centric views, emphasizing measures and flows in concepts such as 'zero waste', 'carbon neutrality', or 'circular economy'.

- Both cities are 'new', meaning they do not take into account any existing contextual parameters.

- This makes them generic and reproducible models for circularity.

- Viewing circular economy from the production and consumption system perspective, they privilege technological and economic dimensions and consider social and environmental dimensions as a result of those.

- They represent circularity coherences in a certain moment, an optimal convergence of technology and economics in Reburg's case, and the application of an ideal 'model' in Masdar City's case. Proposing utopic visions of circularity at a fixed moment in time, they avoid the question of how existing urban fabrics can transition to circularity and become more resilient.

- The images focus on circularity as a product or result that is 'finished' or closed. As synchronic imaginaries, they ignore cities' temporal dimension, the city as process.

From systems ecologists, such as Odum in 1983 [62], over the 1960s Japanese Metabolism movement, cities have indeed been recognized as organisms [63] or ecologies [64] that develop and continuously redevelop. They are in themselves while progressing and inherently going through cycles of investment and reinvestment, development and redevelopment. Cyclic processes are in city development's nature, and it is exactly these processes supporting circularity drivers that Reburg and Masdar City lack.

The two remaining cases, R-urban and Living Breakwaters, exemplify a constructivist worldview. Both projects engage with social and cultural dimensions in existing urban fabrics and act from within these urban fabrics, taking an activist or emancipatory stance. The R-urban strategy captures existing community capacity and energy as well as locally available material resources. R-urban considers the process to reach circularity, while building resilient communities is more important than the final result. In R-urban circularity reframes resources in local scale short circuits as 'commons', as an alternative sociopolitical system that is inclusive, ecological and post-growth. R-urban inscribes itself in the disciplinary field of political ecology, denouncing reigning capitalist sociotechnical regimes by a bottom-up alternative proposal considering local materials resources as 'commons'. Opposing to existing political contexts, R-urban is essentially an activist spatial practice, not compromising on the values of solidarity and resilience that are written down in its charter. Even though initially approved by the municipality, R-urban's physical artefacts were eradicated from Colombes in favor of a new parking lot. This indicates that the vision might never have truly aligned with official policies. Nevertheless, seeds of an alternative, inclusive, and resource-conscious way to inhabit the world and to share its resources were planted within the involved community actors and might reappear as offshoots of this radical initiative.

Finally, Living Breakwaters approaches circularity in a holistic way, interweaving risk reduction with ecology and culture. The imaginary (Figure 5) articulates a multi-scalar understanding of the region's natural systems in relation to human activities. This understanding forms the basis for a strategy addressing risk reduction, habitat creation, and social resilience. Working with nature's capacities to reduce storm surge and regenerate coastal ecosystems, the project reduces the material resources that are required to construct infrastructures. The imaginary functions as a guiding image for site-specific post-disaster process support. Scapestudio "reconceives urban landscape design as an activist practice that unites social and ecological systems to sustainably remake our 
cities" [64]. Evaluating from the project continuity and ongoing side projects, Living Breakwaters indeed embeds a proposal for coastal resiliency in its specific spatial, cultural, social, and ecological context, interconnecting flows and spaces. As such, Living Breakwaters embodies a multi-scalar, place-specific, and context-based interpretation of circularity, working with available material and situational assets and resources connecting ecosystems across scales.

Living Breakwaters and R-urban both emphasize 'circular' resilience as a close relationship between citizens, the territories that they inhabit, and the resources that they consume and produce. In summary:

- Both representations articulate emancipatory political positions, acting from within the site to achieve radical change. In a way acting from within the site means setting up a process that is starting from (the critique of) the existing, a dialectic between the existing and needed. R-urban hereby explicitly emphasizes the need to act against reigning capitalist sociotechnical regimes in any European city and community, drastically changing the way that resource flows are governed. Living Breakwaters, on the other hand, reimagines a concrete site and situation, Staten Island's post-disaster coastal area.

- Both of the projects envision dramatic societal change in the way resource flows, communities, and spaces are interacting. Even though both AAA and Scapestudio label themselves as 'activist' spatial practices, R-urban expresses a more radical societal critique than Living Breakwaters, and explicitly constructs alternatives for reigning regimes initiating a post-growth society from the margin. Living Breakwaters, on the other hand, works with transformative powers within existing institutions in a more consensus-driven and pragmatic practice. It tries to shift spatial practices and intergovernmental collaborations from within, explicitly engaging as many actors and stakeholders as possible to achieve resilience, making use of available situational and material resources that it can capture. The continuous reception and appropriation of Living Breakwaters on both community as well as local, state, and federal level since 2013, seem to indicate successful and supported long-term project engagements.

- Both of the projects privilege social, ecological, and cultural dimensions, and consider technology and economy as secondary driving forces.

- The images are dialectic, building new syntheses through images as a method of intellectual investigation supporting dialogue.

In conclusion, objectivism and constructivism represent two essentially opposing circularity sustainability framings, which are more or less materialized in the four studied imaginaries. On the objectivist end of the spectrum, Reburg and Masdar City spatialize a technology and entrepreneurial 'applied' circular economy. In Reburg's case, this could be interpreted as a neoliberal economy underpinning growth, putting circularity in the hands of businesses. Masdar City, on the other hand, is a state-driven initiative, yet Cugurullo, who studied Masdar City's development policy context, evaluated Masdar City as "urban environmentalism almost exclusively in economic terms" and "a high-tech urban development informed by market analysis rather than ecological studies" [65]. Where Masdar City and Reburg seem to focus on maximally 'recycling' materials in a growing economy, r-urban and Living Breakwaters seem to approach circularity from the perspective of 'reducing' resource consumption. R-urban emphasizes resource sobriety by disconnecting material flows from capitalist market mechanisms and Living Breakwaters partially avoids land and materials consumption, making use of nature's regenerative capacities and the available situational resources. As Vandenbroeck notes, with the shift from objectivism to constructivism comes a critique that is drawing attention to space's political character. Rather than a neutral canvas, space becomes a scene exposing uneven power relations [34]. From the constructivist side, R-urban and Living Breakwaters consider 'closing resource cycles' as an opportunity to shift to a city of sharing, empathy, and cooperation. As such, they position themselves against reigning neoliberal planning agendas, the most explicitly in R-urban's case. The studied 'constructivist' imaginaries essentially support an emancipatory and open development 
process, recognizing becoming and developing as a part of this process. From the practical viewpoint of designing urban circularity, Masdar City and Reburg design circular material flows themselves, making abstraction of the existing context. On the other hand, R-Urban and Living Breakwaters design 'with' circular material flows, acknowledging the existing context and integrating political stances [36].

\subsubsection{Proximity versus Connectivity}

Reburg and R-urban can be understood as spatial structures that are based on connective networks. In the case of Reburg connectivity coincides with the smart city idea, using data monitoring supporting efficient circular material flows in innovative urban circular economies. Reburg functions "like a brain, self-regulated through feedback systems among wired citizens and urban actors" [34,35]. On the other hand, in R-urban, connectivity relationships are material, cultural, temporal, and political, physically connecting community places and actors through 'common' resource flows.

Both Masdar City and Living Breakwaters can be considered as spatial structures that are based on proximity. In Masdar City, state of the art infrastructure and technology close resource loops and minimize waste within "spatially localized constellations of complementary stocks and sinks" [34,35]. Living Breakwaters considers the bioregion its resource context, connecting the local site to relevant larger-scale ecosystems, such as regional water dynamics. It restores the coast's historical natural protection oyster reef structure and makes use of the coastal ecosystem's regenerative capacity. Besides valorizing site-specific qualities, Living Breakwaters reinforces local governance and local anchoring of employment and productive capacity. It maintains context specific balances between humans and their environment. Considering the urban bioregion as the constituent framework, the imaginary serves as a guiding image for agency in coastal protection $[34,35]$.

\subsubsection{Resource Efficiency}

From a resource efficiency standpoint, R-urban and Masdar City focus on closing material loops within the city. Not necessarily taking into account larger scales or resource hinterlands, these two projects quantify and optimize their resource flows through material flow analysis. In R-urban percentages of how much resources could be saved support the resource exchanges (Figure 2a). For example, harvesting rainwater on the roofs could reduce water consumption for habitat with $50 \%$. Setting up the R-urban network also comes with social benefits, such as the creation of 20 new jobs. In Reburg and Living Breakwaters, quantitative aspects are less emphasized, supposedly quantifying their 'circularity' is more complex since they look across city boundaries. In Reburg, material flows are managed at the most immediate and local level where they can effectively be reused. The fourth case, Living Breakwaters, places the intervention site within a multi-scalar understanding of how, in this case, regional water flows can locally be manipulated through punctual interventions such as breakwater reefs simultaneously constructing species habitats. It looks across city boundaries, investigating the appropriate scales for the studied (eco)systems. Quantitative modeling, such as hydraulic modeling, is nevertheless part of Living Breakwaters, but rather as a means than as an end.

\subsubsection{Spatial Context Characteristics and Sustainability Transitions Drivers}

The four case studies support this Special Issue's statement that diverse contexts play out in different forms of urban transitions and pathways to urban sustainability. The main message from the case study analysis is that not all approaches incorporate 'context specificity' to the same extent. When drivers for the urban sustainability transition are situated in the 'objectivist' end of the spectrum, contextual dimensions appear to be added on to a technocratic base. On the other hand, when the drivers for the urban sustainability transition are situated in the 'constructivist' end of the spectrum, the site's specific social, cultural, natural and spatial context are foundational. How these drivers are determined is further developed in the conclusion (5.3). 


\subsection{Building up a Circularity Drivers Framework for Spatial Practice}

\subsubsection{Four Circularity Agendas}

Philippe Vandenbroeck's framework for urban metabolism spatial practices (see Section 2.2) defines four typologies of urban metabolism approaches that are based on their dominant sustainability framings. This section proposes an interpretation of Vandenbroeck's framework applicable to circular city representations.

In the four case studies, different circularity drivers and agendas can be identified, such as technology, top-down and bottom-up circular economy practices, spatial and socio-cultural contexts. As such, the previous section demonstrates that contemporary circular city representations conceal diverging transition drivers. Each of the discussed cases indeed seems to strongly relate to one of Vandenbroeck's four typologies of metabolism approaches, embodying a certain metabolic agenda that is prioritizing specific circularity drivers.

- A technocratic agenda optimizing flows: Masdar City as industrial-ecological pool table metabolisms, prioritizing resource efficiency, clean technology in sustainable infrastructures conceived from the top down.

- A business-driven agenda innovating with flows: Reburg as 'smart city' web metabolisms that are founded on circular economy business models and digital networks.

- A holistic agenda contextualizing flows: Living Breakwaters as bioregional mosaic metabolisms offering a cultural, multi-scalar, and place-specific circularity approach as restoring ecological cycles.

- An activist agenda democratizing flows: R-urban as narrative metabolisms prioritizing bottom-up community stewardship over resource flows supporting a civic economy in a larger resilience strategy.

Not surprisingly, none of the representations purely embodies one of the circularity agendas. Figure 6 attempts to start concretizing Vandenbroeck's four abstract proposed typologies for spatial practice, combining his descriptions with drivers that were identified in the four cases. For this exercise's practical purpose, Vandenbroeck's 'constructivist' and 'objectivist' framework axes are renamed 'emancipatory' and 'technocratic'. Firstly, the authors listed all of the defined circularity interpretations in the accompanying quadrant. Secondly, they qualitatively compared and assessed the four cases' circularity drivers (Figure 6). The quantitative appreciation along the axes distinguishes the main from secondary circularity drivers driving the studied circularity representations.

Figure 6 demonstrates that each of the imaginaries indeed largely overlaps with one of the four framework quadrants, but enters other quadrants as well. It also demonstrates that the technocratic projects barely enter the emancipatory framework half, whereas the emancipatory projects do also cover some technocratic circularity drivers.

It should be noted that not all epistemological and political dimensions that are defined in Vandenbroeck's framework could be identified in the spatial representations. This tension in applying Vandenbroeck's theoretical framework to four concrete imaginaries is best exemplified in the 'narrative metabolism's spatial concept. In a reaction to a draft version of this paper, Vandenbroeck states that R-urban certainly embodies a few elements of the concept, but that R-urban's charter application misses narrative metabolism's essential layeredness, fragmentation, and complexity. However, Vandenbroeck acknowledges that it is difficult to connect concrete spatial examples to the narrative metabolism concept, and that to his knowledge so far, writers (Vandenbroeck refers to Caroline Levins' 'Forms' interpreting Charles Dickens' 'Bleak House' built up by numerous interconnected and overlapping partially metabolic networks), rather than cartographers, possess the capacity to articulate this fabulous complexity of rampant networks. As with literature's intertextuality, narrative metabolisms imaginaries should be inter projective, incorporating precision while allowing for interpretation from different angles. 

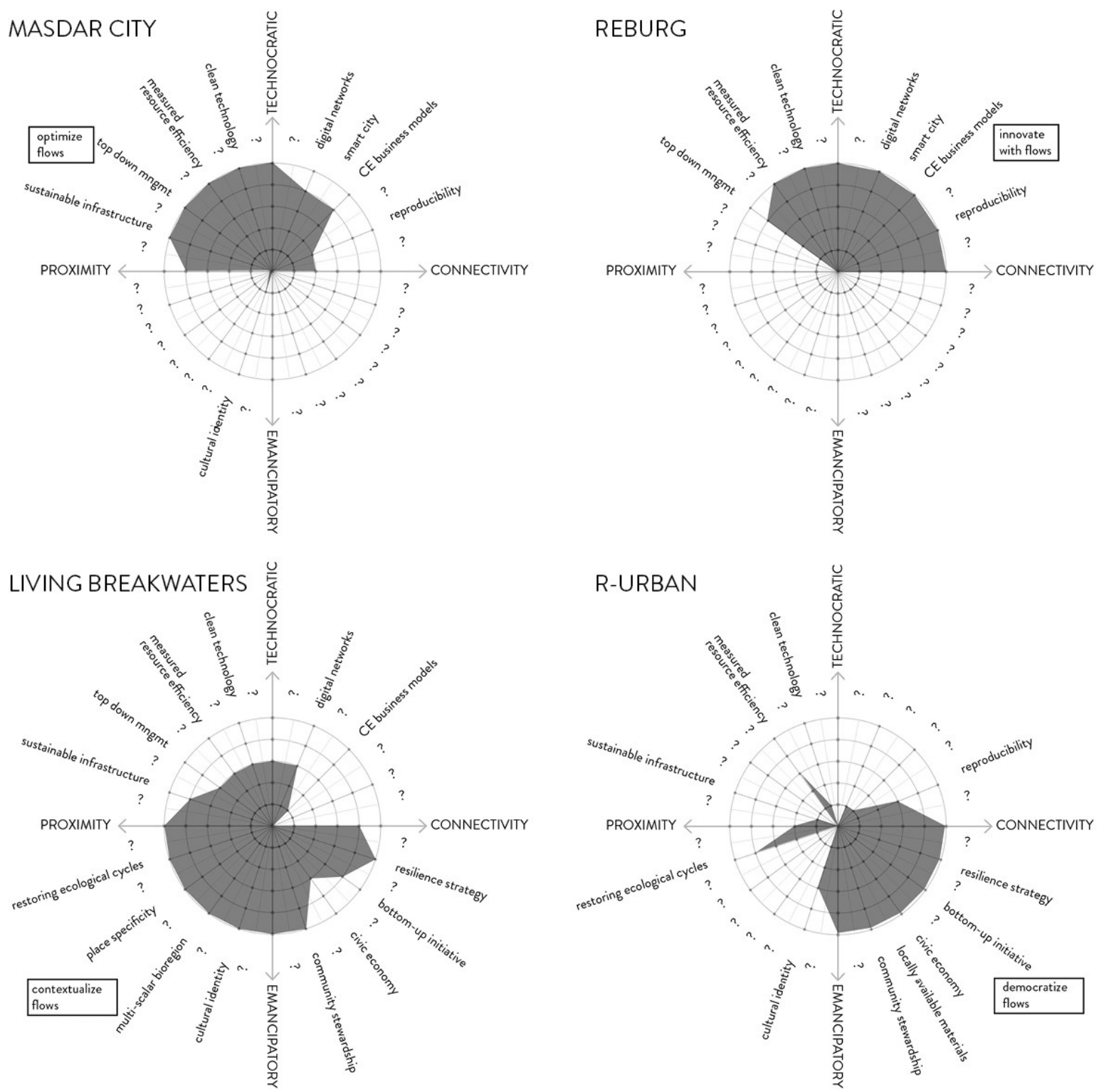

Figure 6. Comparative study of the four circularity imaginaries, interpreting Vandenbroeck's framework.

\subsubsection{Circularity Drivers Framework for Spatial Practice}

Keeping in mind the above-formulated notes, Figure 7 proposes an applied yet incomplete framework to start clarifying and articulating circularity in space. It interprets Vandenbroeck's framework from the perspective of circularity drivers, mixing planning, and design approaches with resource management. Ideally, circular cities would cover the entire spectrum in order to achieve multi-dimensional circularity. However, it is important to note that the proposed framework is not intended as a checklist for circularity or a 'one-fits-all' solution. It is rather an initial attempt to articulate, gather, and frame potential spatial circularity drivers, which are connected to specific 'metabolic agendas' (see Section 4.2.1). Since multiple lower half drivers relate to context-specificity, the outcome of this applied diagram would be different in each situation and incorporate places' specific cultural, socio-economic, or environmental identity.

The proposed framework for spatial circularity:

- is systemic: it aims to relate micro, meso and macro scales within an ideal situation of regenerating ecosystems; 
- envisions how people relate to the ecosystems they inhabit as part of circularity; and,

- combines both technocratic and emancipatory approaches [66], drawing both from management and politics.

The proposed framework should be understood as an initial attempt to structure research and practice on circular cities design. Supplementary project analysis would enable the further refinement of the proposed framework and it is proposed for further research.

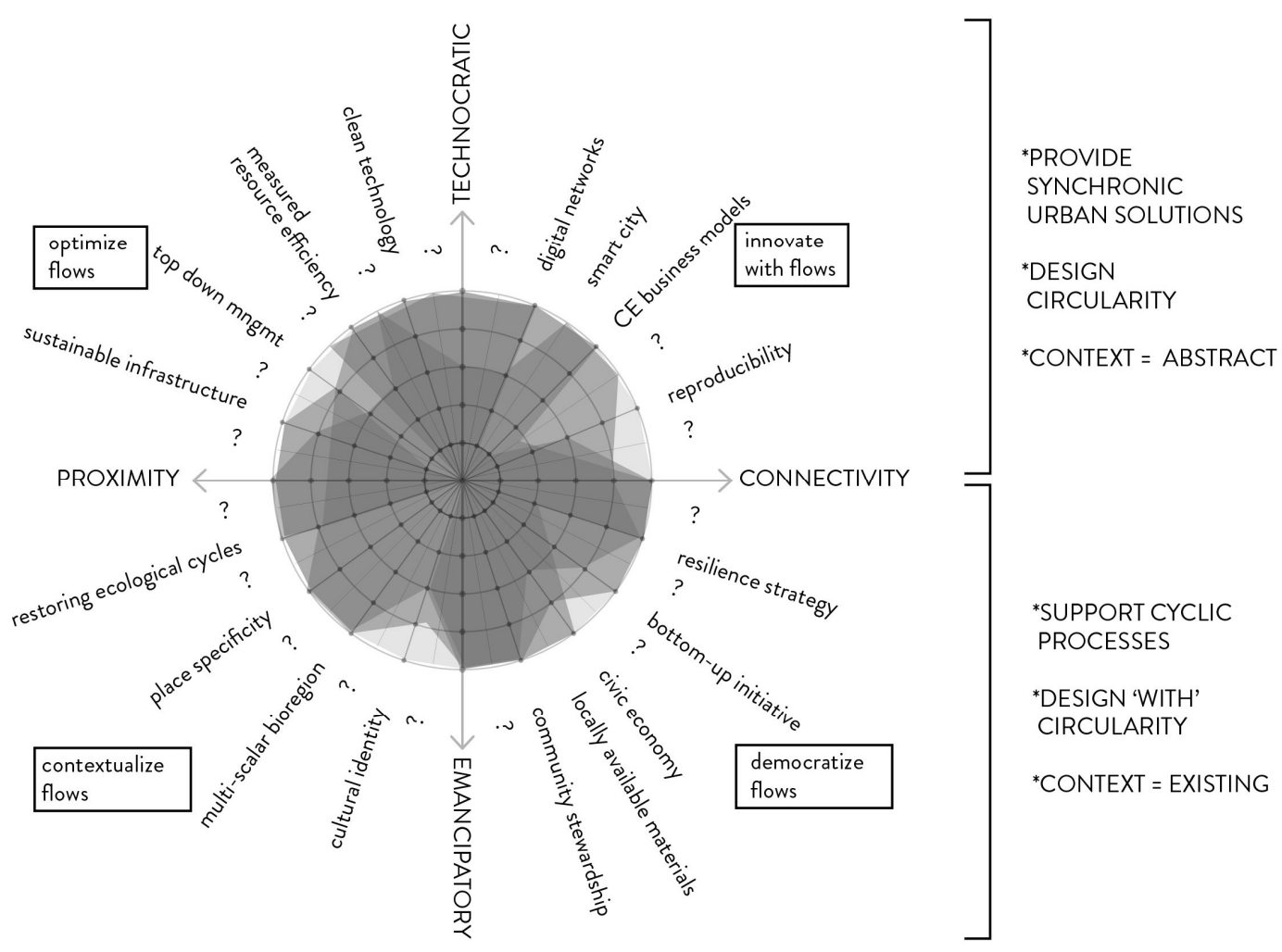

Figure 7. Spatial circularity drivers framework. Interpretation of Vandenbroeck's framework for urban metabolism spatial practices, elaborated by author.

\section{Conclusions}

According to environmental researcher Matutinovic, sustainable development relies, since its conception in the 1970s, on technological progress and market mechanisms that are aiming to preserve the natural environment while maintaining economic growth. Nevertheless, he states that scientists themselves increasingly point to the cultural sphere as the source and solution for sustainability issues. In other words, sustainability is an issue of institutions and worldviews, and can only happen if we "change our overall perspective towards nature, work, leisure and well-being" [40] (p. 1). Additionally, for the case of circular economy, Korhonen et al. suggest more qualitative research methodologies to address circular economy as a paradigm shift [3]. In this light, the conducted comparative case study research suggests the following conclusions.

\subsection{Multi-Dimensional Spatial Circularity Requires Combinations of Different Sustainability Framings}

This paper's comparative case study analysis and the derived spatial circularity drivers framework demonstrate substantial differences in circularity approaches. It clarifies how these differences at least depend on the project's sustainability framing, disciplinary field, and commissioner. Simultaneously, the analysis reveals circularity as a topic that is crossing multiple currently disconnected spatial practice fields representing different sustainability framings. In order to embrace circularity's complexity, 
combinations of different sustainability framings and collaborations between different spatial practices seem to be necessary.

\subsection{Spatial Circularity Representations are Implicitly or Explicitly Political}

Vandenbroeck already addressed that the switch from objectivist to constructivist approaches comes with a critical attitude towards the 'metabolic agenda' [34]. Indeed, R-urban, for example, is explicitly political, opposing against reigning capitalist regimes. However, this does not mean that Masdar City or Reburg have no political dimension. Implicitly, the former spatializes a resource efficiency agenda and the latter a circular economy agenda. Living Breakwaters, on the other hand, spatializes an emancipatory project for an inclusive resilience transition. In other words, implicitly or explicitly, circularity representations always conceal politics that are driving metabolic agendas.

\subsection{The Leading Disciplinary Field and Commissioner Determine which Circularity Drivers are Addressed}

The conducted case study analysis indicates that both the commissioner and the disciplinary field in charge determine metabolic agendas behind circularity representations. Living Breakwaters demonstrates that the more open the design question is, and the earlier that urban landscape designers are involved, the more holistic circularity can be interpreted. In Reburg, the developed future scenarios are a direct, albeit out-of-the-box, answer to the client's question to provoke innovative business thinking. Nevertheless, somewhere in the translation of Plan C's multi-dimensional circularity vision to a spatial proposal, multiple societal dimensions were abandoned. Similarly, in Masdar City, architects were commissioned the spatial design of a city within a given urban framework aiming for maximal resource efficiency, which was driven by material flow analyses. Even though Masdar City's architects developed innovative and qualitative spatial architectural schemes with typological contextual sensitivity, their core task was to realize a client's dream. Finally, R-urban's self-initiated urban transformation process materializes a political stance that is aiming to change the reigning sociotechnical system. It deliberately emphasizes the democratization of resource flows as 'commons'. In a softer activist way, Living Breakwaters openly engages with governments and local communities, considering them as experts and agents in the ecosystems that they inhabit.

\subsection{Urban Landscape Design can Approach Circularity in an Inclusive, Multi-Dimensional, Place-Specific and Multi-Scalar Way}

Figure 7 reveals that the urban landscape design approach, as conducted in Living Breakwaters, covers the broadest range of circularity drivers. Living Breakwaters holistically reframes complex problems that are linked to post-disaster recovery, without limiting itself to administrative boundaries. As such, the urban landscape design approach integrates social, ecological, and economic dimensions in cyclic reconstruction scenarios. Living Breakwaters shows that operating within an 'open' commission, urban landscape design can increasingly add on circularity drivers from different framework quadrants. This is exactly the difference between Living Breakwaters and the three other cases that explicitly articulate certain circularity drivers while excluding others. For example, Masdar City clearly excludes possible exchanges with its regional hinterland. It is synchronic by definition as an isolated new town model. Reburg appears to be even more exclusive, imagining the city as the sum of what is for sale in the 'Circularity Fair'. R-urban explicitly takes an anti-capitalist political position, excluding the business and efficiency driven dimensions overarching in Masdar City and Reburg. Living Breakwaters, on the other hand, is inclusive in its aim to interweave risk reduction with culture and ecology. Departing from Staten Island's existing spatial context, its challenges and opportunities, it offers a framework to absorb dimensions that are represented in any of the other three projects, even if they are contradictory. Living Breakwaters' images bring new syntheses of circularity, open to cyclic change, not necessarily identifying with one of the four framework quadrants. This leads to the hypothesis that urban landscape design seems to have a capacity to act as a pivot in transdisciplinary Spatial Circularity Design Research. 


\subsection{Urban Landscape Design Can Act as a Pivot in Transdisciplinary Spatial Circularity Design Research}

Korhonen et al. suggest that circular economy research requires research on the paradigm, as well as on the practice shift, encompassing virtually all levels from global down to the individual [1].

Designing and engineering is by definition making, fabricating, and combining things. Future imaginaries, such as Living Breakwaters, which are produced by urban landscape designers, seem to have the capacity to capture components of circular economy as a multi-dimensional and multi-scalar paradigm and practice. Multi-dimensional circular city representations require expertise and input from a number of disciplines, ranging from industrial ecology's material flow analysis over participatory planning's co-creation strategies, political ecology's criticality, and ecological economics' business perspective. Figure 8 proposes a transdisciplinary constellation for forward-looking spatial research on circularity, with urban landscape design as the pivot between disconnected disciplinary fields addressing circularity. The proposed transdisciplinary circularity research framework indicates how philosophies and methods from different disciplinary fields could feed urban landscape design when imagining the multi-dimensional spatial circularity transition. Additionally, Figure 8 partially integrates Korhonen et al.'s research framework for circular economy research, distinguishing two research levels with increasing complexity. Level 1 focuses on applied circular economy, mainly adopting quantitative tools, metrics, instruments, and indicators, while level 2 is more qualitative and addresses circular economy norms, values, visions, and concepts. Urban landscape design is positioned at the center of Korhonen et al.'s diagram, reflecting its potential pivot role in transdisciplinary spatial circularity design research [1].

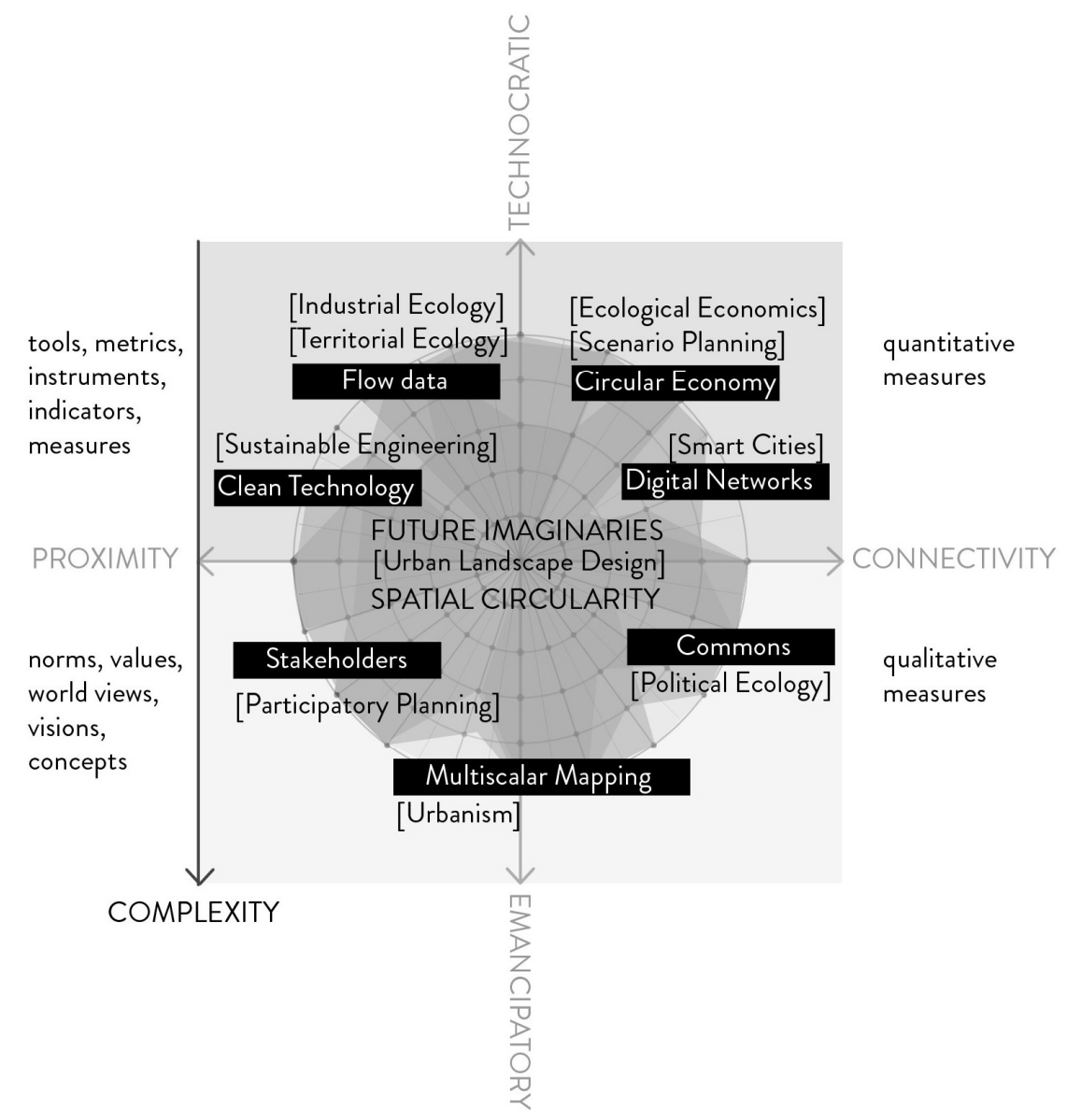

Figure 8. Proposed transdisciplinary framework for forward-looking spatial circularity design research, placed in Korhonen et al.'s theoretical framework for positioning circular economy research [3] (p. 549). Urban landscape design as a hinge between different disciplines. By authors. 


\subsection{An Agenda for Spatial Circularity Assignments}

From their study of six cities in circular economy transition, Prendeville et al. concluded "that political leadership, building adaptable future visions, using experimental approaches (such as living labs), developing contextual knowledge about resource use, and engaging with diverse stakeholders are important" [12] (p. 1).

Urban landscape design's expected capacity to merge knowledge from multiple circular economy disciplines draws from urban design originally merging two spatial design disciplines, urban design and landscape architecture. With its many 'spheres of urbanistic action' [67] that are operating at the intersection of disciplines, such as ecology, engineering, design, programming, and social policy, Urban Design essentially brings together contradictions in policy domains, operation scales, different visions, etc. Traditionally starting with an existing spatial context, urban design addresses specific situations in particular places, deals with the city's physical form and its relationships with surroundings, independent from preconceived boundaries [68]. When combined with landscape architecture's emphasis on territories' dynamic and fluid character [69,70], urban landscape design is essentially concerned with the environment as living matter, focusing on the process of change, rather than on final images or outcomes. For example, in their vision for Circular Buiksloterham in Amsterdam, DELVA, Metabolic and Studioninedots propose a broader understanding of circularity from their landscape design perspective. They acknowledge that technology based disruptive revenue models on a city do not leave room for complexity when it comes to developing circularity in urban development. Alternatively, they propose three layers for the new circular city: new genius loci, programming for circularity, and working at local exchanges of circular building blocks [71]. Furthermore, Rebuild by Design's 2013 Hurricane Sandy Competition appointed urban and landscape designers to synthesize and connect seemingly disparate challenges, opportunities, and expertise through design, acting as a pivot between experts, communities, and policymakers. Following this effort with urban landscape designers clarifying, framing, and imagining how to approach complex post-disaster challenges, Rebuild by Design's research-based and collaborative design processes became a model for other governments to prepare for future risk challenges, such as the United States Bay Area [48]. Finally, landscape architect Dirk Sijmons studied the interplay between the energy transition to renewable energy and the landscape in his book 'landscape and energy, designing transition'. He imagines possible scenarios for post-fossil fuel futures through design in concrete case studies. Through this forward-looking research by design approach, Sijmons synthesizes economic, technical, political, and even emotional energy transition dimensions [72].

In conclusion, this research recommends further (action) research on the potential role of urban landscape design to support a multi-dimensional place-specific circular economy transition, consisting of:

- Forward looking urban landscape design research, in particular places in circular economy transition.

- Open questions and policy frameworks allowing holistic approaches not defending one client in particular, but aiming for resource efficiency integrating material, social, economic and environmental dimensions across political agendas.

- Multi-actor and multilevel support on community, local and higher government levels

- Multidisciplinary design teams integrating industrial ecology, scenario planning, political ecology, and other relevant expertise.

Author Contributions: Julie Marin conceived, designed and performed the project analysis. She also wrote the paper with Bruno De Meulder, who supervised the research.

Acknowledgments: This research is funded by the Research Foundation-Flanders (FWO). The authors wish to thank Philippe Vandenbroeck for the generous exchanges about his theoretical framework as well as for his constructive and critical responses to draft versions of this article throughout the conception and writing phase. They also wish to thank Nadia Mirabella and the blind reviewers for their useful comments and feedback on the paper. Finally, also thank you to Hanne Van Gils and Sarah Soontjens for their feedback and Jolein Bergers for her help with proofreading. 
Conflicts of Interest: The authors declare no conflict of interest. The founding sponsors had no role in the design of the study; in the collection, analyses, or interpretation of data; in the writing of the manuscript, and in the decision to publish the results.

\section{References}

1. Korhonen, J.; Cali, N.; Feldman, A.; Seyoum Esthetu, B. Circular economy as an essentially contested concept. J. Clean. Prod. 2018, 175, 544-552. [CrossRef]

2. Ghisellini, P.; Cialani, C.; Ulgiati, S. A review on circular economy: The expected transition to a balanced interplay of environmental and economic systems. J. Clean. Prod. 2016, 114, 11-32. [CrossRef]

3. Merli, R.; Preziosi, M.; Acampora, A. How do scholars approach the circular economy? A systematic literature review. J. Clean. Prod. 2018, 178, 703-722. [CrossRef]

4. Bocken, N.; Olivetti, E.; Cullen, A.; Jonathan, M.; Potting, J.; Lifset, R. Taking the Circularity to the Next Level: A Special Issue on the Circular Economy. J. Ind. Ecol. 2017, 21, 476-482. [CrossRef]

5. Kirchherr, J.; Reike, D.; Hekkert, M. Conceptualizing the circular economy: An analysis of 114 definitions. Resour. Conserv. Recycl. 2017, 127, 221-232. [CrossRef]

6. Korhonen, J.; Honkasalo, A.; Seppälä, J. Circular Economy: The Concept and its Limitations. Ecol. Econ. 2018, 143, 37-46. [CrossRef]

7. Prieto-Sandoval, V.; Jaca, C.; Ormazabal, M. Towards a consensus on the circular economy. J. Clean. Prod. 2018, 179, 605-615. [CrossRef]

8. Pomponi, F.; Moncaster, A. Circular economy for the built environment: A research framework. J. Clean. Prod. 2017, 143, 710-718. [CrossRef]

9. Ellen MacArthur Foundation. Towards the Circular Economy Vol. 1. 2013. Available online: https://www.ellenmacarthurfoundation.org/publications/towards-the-circular-economy-vol1-an-economic-and-business-rationale-for-an-accelerated-transition (accessed on 28 January 2018).

10. Ford, H. Learning from waste. In Today and Tomorrow; Productivity Press: Cambridge, MA, USA, 1926; pp. 91-100.

11. Meadows, D.H.; Meadows, D.L.; Randers, J. The Limits to Growth: A Report for the Club of Rome's Project on the Predicament of Mankind Meadows, 2nd ed.; Donella, H., Meadows, D., Randers, J., Eds.; New American Library: New York, NY, USA, 1975.

12. Prendeville, S.; Cherim, E.; Bocken, N. Circular Cities: Mapping Six Cities in Transition. Environ. Innov. Soc. Transit. 2017, 26, 171-194. [CrossRef]

13. Ellen MacArthur Foundation. Schools of Thought. Available online: https:/ /www.ellenmacarthurfoundation. org/ circular-economy / schools-of-thought (accessed on 13 March 2018).

14. Ellen MacArthur Foundation. Delivering the Circular Economy: A Toolkit for Policymakers. Available online: https://www.ellenmacarthurfoundation.org/publications / delivering-the-circular-economy-atoolkit-for-policymakers (accessed on 13 March 2018).

15. Arnsperger, C.; Bourg, D. Vers une économie authentiquement circulaire. Revue de l'OFCE 2016, 145, 91-125. [CrossRef]

16. McDowall, W.; Geng, Y.; Huang, B.; Barteková, E.; Bleischwitz, R.; Türkeli, S.; Kemp, R.; Doménech, T. Circular Economy Policies in China and Europe. J. Ind. Ecol. 2017, 21, 651-661. [CrossRef]

17. European Commission. Closing the Loop: An EU Action Plan for the Circular Economy. 2015. Available online: http:/ / eur-lex.europa.eu/legal-content/EN/TXT/?uri=CELEX:52015DC0614 (accessed on 13 March 2018).

18. Ellen MacArthur Foundation. Circular Cities Network. Available online: https://www.ellenmacarthurfoundation. org/news/circular-cities-network (accessed on 13 March 2018).

19. Municipality of Amsterdam. Sustainable Amsterdam, Agenda for Renewable Energy, Clear Air, a Circular Economy and A climate-Resilient City; Municipality of Amsterdam: Amsterdam, The Netherlands, 2015; 76p, Available online: http:/ / urbantransform.eu/wp-content/uploads/sites/2/2013/02/Sustainable_Amsterdam_27-32015.pdf (accessed on 20 April 2018).

20. Van Winden, W.; Oskam, I.; Van den Buuse, D.; Schrama, W.; Van Dijck, E.J. Organising Smart City Projects: Lessons from Amsterdam; Hogeschool van Amsterdam: Amsterdam, The Netherlands, 2016; 126p, Available online: http:/ / www.hva.nl/carem/gedeelde-content/publicaties/publicaties-algemeen/2016/organisingsmart-city-projects.html (accessed on 20 April 2018). 
21. Glasgow Chamber of Commerce; Zero Waste Scotland; Glasgow City Council; Circle Economy. Circular Glasgow: A Vision and Action Plan for the City of Glasgow; Glasgow Chamber of Commerce, 2016; 31p. Available online: https: / /www.circle-economy.com/wp-content/uploads/2016/06/circular-glasgow-report-weblow-res.pdf (accessed on 20 April 2018).

22. Mairie de Paris. Une économie sociale et solidaire. In Livre Blanc de l'économie circulaire du Grand Paris; ADEME: Marseille, France, 2015; Available online: https:/ /api-site-cdn.paris.fr/images/ 75577 (accessed on 10 April 2018).

23. Ellen MacArthur Foundation. Cities in the Circular Economy: An Initial Exploration. 2017. Available online: https: / / www.ellenmacarthurfoundation.org/publications/cities-in-the-circular-economy-an-initialexploration (accessed on 28 January 2018).

24. Vandenbroeck, P. Working with Wicked Problems; The King Baudouin Foundation: Brussels, Belgium, 2012; 50p.

25. Loorbach, D.; Rotmans, J. Transities E Transitiemanagement. Oorsprong, Status en Toekomst; Drift: Rotterdam, The Netherlands, 2012; 8p.

26. Bugge, M.; Capasso, M.; Finne, H.; Hansen, T.; Klitkou, A.; Normann, H.; Steen, M. Geography of Sustainability Transitions. In Proceedings of the 4th Geography of Innovation Conference, Barcelona, Spain, 31 January-2 February 2018; Available online: http:/ / geoinno2018.com/geography-of-sustainabilitytransitions / (accessed on 28 January 2018).

27. Coenen, L.; Benneworth, P.; Truffer, B. Toward a spatial perspective on sustainability transitions. Res. Policy 2012, 41, 968-979. [CrossRef]

28. Groat, L.N.; Wang, D. Architectural Research Methods; Monacelli: New York, NY, USA, 2002.

29. Shuttleworth, M. Case Study Research Design. 2008. Available online: https://explorable.com/case-studyresearch-design (accessed on 16 March 2018).

30. Yin, R.K. Case Study Research: Design and Methods, 2nd ed.; Sage Publications: Thousand Oaks, CA, USA, 1991; ISBN 0-8039-3470-X.

31. Rittel, H.; Webber, M.M. Dilemmas in a General Theory of Planning. Policy Sci. 1973, 4, 155-169. [CrossRef]

32. Viganò, P. Les Territoires de l'urbanisme, le Projet Comme Producteur de Connaissance; Metis Presses: Paris, France, 2014; ISBN 978-2-940406-61-6.

33. Vandenbroeck, P. Whither Urban Metabolism. In Urban Design Strategies; KU Leuven: Leuven, Belgium, 2017.

34. Vandenbroeck, P. Een Metabolische Manier van naar de Wereld Te Kijken; Labo Ruimte: Brussels, Belgium, 2017; unpublished.

35. Atelier Brussels. Three Designing with Flows Masterclasses. Available online: http:/ / www.architectureworkroom. eu/atelierbrussel/masterclass-designing-with-flows (accessed on 28 January 2018).

36. Vandenbroeck, P. Designing with flows. In Towards an Urban-Metabolic Agenda for a Circular Future; OVAM, FABRIC, VMM, Team Vlaams Bouwmeester and Metabolism of Cities: Brussels, Belgium, 2017; 25p.

37. OVAM, Stand van zaken Vlaams Materialenprogramma. Clusters en randvoorwaarden. Available online: https: / www.vlaanderen.be/nl/publicaties / detail/stand-van-zaken-vlaams-materialenprogrammaclusters-en-randvoorwaarden (accessed on 15 March 2018).

38. Baccini, P.; Brunner, P. Metabolism of the Anthroposphere: Analysis, Evaluation, Design, 2nd ed.; The MIT Press: Cambridge, MA, USA, 2012; ISBN 978-0-262-01665-0.

39. Castan Broto, V.; Allen, A.; Rapoport, E. Interdisciplinary Perspectives on Urban Metabolism. J. Ind. Ecol. 2012, 16, 851-861. [CrossRef]

40. Matutinović, I. An Institutional Approach to Sustainability: Historical Interplay of Worldviews, Institutions and Technology. J. Econ. Issues 2007, 41, 1109-1137. [CrossRef]

41. Beinfield, H.; Korngold, E. Handboek Chinese Geneeswijzen: Theorie, Typologie en Therapie, 7th ed.; Altamira11: Haarlem, The Netherlands, 2016; ISBN 9789401302418.

42. Vlaanderen Circulair. Samen Werken aan Circulaire Economie in Vlaanderen. Available online: http:/ / www.vlaanderen-circulair.be/nl (accessed on 28 January 2018).

43. Pantopicon. Welcome to Reburg-The Circular City. Available online: http://pantopicon.be/portfolio/ welcome-to-reburg-the-circular-city/ (accessed on 28 January 2018).

44. Plan C, Pantopicon, Welcome to Reburg. Available online: www.reburg.world (accessed on 28 January 2018).

45. R-urban, About R-urban. Available online: http://r-urban.net/en/sample-page/ (accessed on 28 January 2018).

46. Hopkins, R. The Transition Handbook: From Oil Dependency to Local Resilience; Hopkins, R., Ed.; Foxhole Green Books: Foxhole, UK, 2008; ISBN 9781900322188. 
47. Petcou, C.; Petrescu, D. R-urban Resilience. In Atlas Geography Architecture and Change in an Interdependent World; Yszczuk, R., Smith, J., Clark, N., Butcher, M., Eds.; Black Dog Publishing: London, UK, 2011; ISBN 1-907317-39-2.

48. Atelier d'Architecture Autogérée. Available online: www.urbantactics.org (accessed on 28 January 2018).

49. Le Parisien, L'Agrocité déménagée de force de Colombes vers Gennevilliers. Available online: http: / / www.leparisien.fr/colombes-92700/1-agrocite-demontee-de-force-a-colombes-20-02-2017-6695853.php (accessed on 28 January 2018).

50. Telerama. A Colombes, l'écologie citoyenne perd une bataille (mais pas la guerre). Available online: http: / www.telerama.fr/sortir/a-colombes-l-ecologie-citoyenne-perd-une-bataille-mais-pas-laguerre,155117.php (accessed on 28 January 2018).

51. Masdar City. Available online: https:/ / en.wikipedia.org/wiki/Masdar (accessed on 28 January 2018).

52. Veolia. Masdar City, a Zero-Waste, Zero-Carbon City in the Desert. Available online: http://www. livingcircular.veolia.com/en/lifestyle/masdar-city-zero-waste-and-zero-carbon-desert (accessed on 28 January 2018).

53. Masdar City @ Foster + Partners. Available online: https://www.fosterandpartners.com/projects/masdar-city/ (accessed on 23 April 2018).

54. The Guardian, Masdar's Zero-Carbon Dream Could Become World's First Green Ghost Town. Available online: https: / www.theguardian.com/environment/2016/feb/16/masdars-zero-carbon-dream-couldbecome-worlds-first-green-ghost-town (accessed on 28 January 2018).

55. Scapestudio. Living Breakwaters Competition. Available online: http://www.scapestudio.com/projects / living-breakwaters-competition/ (accessed on 28 January 2018).

56. Rebuild by Design in partnership with 100 resilient cities. Available online: http:/ / rebuildbydesign.org/ (accessed on 28 January 2018).

57. The NY Governor's Office of Storm Recovery New York. Available online: https:/ / stormrecovery.ny.gov / LBWCAC (accessed on 28 January 2018).

58. Transitienetwerk Middenveld. Toekomstvisie. Available online: http:/ /www.transitienetwerkmiddenveld. be/over-ons/toekomstvisie (accessed on 28 January 2018).

59. Transitienetwerk Middenveld, Betergem. Available online: http://www.transitienetwerkmiddenveld.be/ 157-een-gelukkig-2038-gewenst (accessed on 28 January 2018).

60. Barles, S. Society, energy and materials: The contribution of urban metabolism studies to sustainable urban development issues. J. Environ. Plan. Manag. 2010, 53, 439-455. [CrossRef]

61. The Guardian, Reaching New Heights. Available online: https://www.theguardian.com/environment/ 2008/jan/30/carbonemissions.climatechange (accessed on 28 January 2018).

62. Bélanger, P. Landscape Infrastructure. Urbanism beyond Engineering; Wageningen University: Wageningen, The Netherlands, 2013; p. 407.

63. Antoniou, V. City as an Organism: Paradigms for the Practice of Urban Design. Available online: https: / /www.scribd.com/document/97432027/City-as-an-Organism (accessed on 16 March 2018).

64. Orff, K. Toward an Urban Ecology; The Monacelli Press: New York, NY, USA, 2016; 272p, ISBN 9781580934367.

65. Cugurullo, F. Urban eco-modernisation and the policy context of new eco-city projects: Where Masdar City fails and why. Urban Stud. 2016, 53, 2417-2433. [CrossRef]

66. Kampelmann, S. On the circularization of territorial metabolism. In Designing Territorial Metabolism: Metropolitan Studio on Brussels, Barcelona, and Veneto; Grulois, G., Tosi, M.C., Crosas, C., Eds.; Jovis: Berlin, Germany, 2018.

67. Krieger, A. Where and How Does Urban Design Happen? In Urban Design; Krieger, A., Saunders, W., Eds.; University of Minnesota Press: Minneapolis, MN, USA, 2003.

68. Urban Design. Condensed Report of an Invitation Conference Sponsored by Faculty and Alumni Association of Graduate School of Design, Harvard University, April 9-10, 1956. Progress. Archit. 1956, 8, 97-112.

69. McHarg, I. Design with Nature, xth ed.; John Wiley \& Sons, Inc.: New York, NY, USA, 1992; ISBN 9780471114604.

70. Corner, J. Terra fluxus. In Landscape Urbanism Reader; Waldheim, C., Ed.; Princeton Architectural Press: New York, NY, USA, 2006. 
71. Delva Landscape Architects, Studioninedots, Metabolic. Circular Cities-Designing post-Industrial Amsterdam-The Case of Buiksloterham. Available online: https://issuu.com/delvalandscape/docs/ circularcities_designing_post_indus/55 (accessed on 15 March 2018).

72. Sijmons, D. Landscape and Energy: Designing Transition; Sijmons, D., Ed.; nai010: Rotterdam, The Netherlands, 2014; 432p, ISBN 97-94-6208-113-0. 